\title{
Economic burden associated with chronic constipation in Sweden: a retrospective cohort study
}

This article was published in the following Dove Press journal:

ClinicoEconomics and Outcomes Research

12 August 2014

Number of times this article has been viewed

\author{
Sara Bruce Wirta' \\ Paul Hodgkins ${ }^{2}$ \\ Alain Joseph ${ }^{3}$ \\ 'IMS Health, Stockholm, Sweden; \\ ${ }^{2}$ Shire, Wayne, PA, USA; ${ }^{3}$ Shire, \\ Eysins, Switzerland
}

Background: Chronic constipation is a common condition, but few studies have assessed its cost and impact on resource use. The purpose of this cohort study was to assess the health care utilization and costs of chronic constipation in a Swedish population using health care claims data.

Methods: Data were compiled on health care costs, drug costs, and mortality for Västra Götaland, Sweden (2005-2009). These data were used to identify patients aged 18 years or older with chronic constipation, defined as: at least two health care contacts with a primary diagnosis of constipation within 12 months or at least one care contact with a primary diagnosis of constipation and two dispatches of laxatives 6 months before and 12 months after the index date. Patients with irritable bowel syndrome or taking opioids, both of which can cause constipation, were excluded. Costs, resource use, comorbidities, and laxative use were assessed during a 12-month follow-up period.

Results: In total, 4,043 patients with chronic constipation were identified. They had a mean (SD) age of $67 \pm 18$ years. Mortality was $7 \%$ during the 12 -month follow-up period and the most common comorbidity was hypertension (22\%). In the 12-month follow-up period, patients with chronic constipation had a mean (SD) of $2.3 \pm 7.5$ constipation-related health care contacts and a mean (SD) of $15.2 \pm 19.5$ other health care contacts. Annual costs, adjusted for sex, age group, mortality, and comorbidities, were $€ 5,388$, of which $€ 951$ were for constipation-related care.

Conclusion: Patients with chronic constipation constituted an elderly population with a high disease burden in Sweden between 2005 and 2009. Mean annual constipation-related health care costs, adjusted for potentially confounding factors, were $€ 951$ per patient.

Keywords: cohort study, chronic constipation, costs, Sweden

\section{Introduction}

Chronic constipation is a common gastrointestinal disorder defined by the Rome III criteria as the presence of constipation symptoms for the last 3 months with symptom onset at least 6 months before diagnosis. ${ }^{1}$ The condition is initially managed with diet and lifestyle changes, followed by use of over-the-counter or prescription laxatives and enemas. Recently, novel drugs such as prucalopride, linaclotide, and lubiprostone have also become available.

The exact prevalence of chronic constipation has been hard to establish, with a recent systematic review finding a global prevalence ranging from $2.5 \%$ to $79 \%$ in adults, with a median of $16 \% .{ }^{2}$ A patient survey in the USA described a considerable duration of chronic constipation, with $21 \%$ of respondents (117 of a total of 557) reporting having had symptoms for 10 years. ${ }^{3}$ The prevalence of chronic constipation appears
Correspondence: Sara Bruce Wirta IMS Health, Sveavägen 155 (Plan 9), Stockholm II 346 , Sweden

Tel +460734324108

Fax +460850884299

Email sbruce-wirta@se.imshealth.com 
to increase with age ${ }^{4}$ however, there is some debate in the literature about the effect of aging on constipation, and this increased prevalence may be due to increased self-reporting of constipation in elderly populations or to an increase in constipation secondary to other causes. ${ }^{4,5}$ A predominance of constipation in women has been reported worldwide, with a median and mean female/male ratio of 1.5 and 2.1, respectively. ${ }^{2,4}$ A population-based survey of bowel habits in Sweden found that $14 \%$ of 1,610 adults had self-reported constipation; this rose to $20 \%$ among women. ${ }^{6}$ In addition, $22 \%$ of elderly women and $10 \%$ of elderly men reported using laxatives in this survey. ${ }^{6}$

Studies in several countries, including the USA, have shown that the burden on health care resources associated with chronic constipation is substantial. ${ }^{7,8}$ A study of a US health maintenance organization found that mean total annual health care costs (including inpatient and outpatient costs, prescription and nonprescription medication costs, and the costs of alternative therapies) were US\$7,522 (95\% confidence interval [CI] 5,689-9,146) for patients with constipation in 2001-2002. ${ }^{7}$ A second study in the USA found that the total direct health care costs for patients with constipation in the California Medicaid system were US\$18,891,008 (US\$246 per patient) when these costs were calculated over a 15-month period during 1995-2003. ${ }^{8}$

There is, however, a lack of comprehensive studies that have assessed the economic and health-related burden of chronic constipation in Sweden. We therefore performed a systematic analysis of Swedish health care records, with the aim of estimating the economic burden and resource utilization associated with chronic constipation in adults.

\section{Materials and methods Data sources}

Data were compiled from health records in the Västra Götaland region of south-west Sweden and combined with data from the National Health Registers of Drug and Mortality, as previously described. ${ }^{9}$ The Västra Götaland region has a population of approximately 1.5 million, with an age distribution similar to that of the nation as a whole; the region has a representative mix of urban and rural populations. ${ }^{10}$ The records available included complete data for over $99 \%$ of all health care contacts (drawing from nine hospitals and 1,018 outpatient clinics and primary care clinics), including inpatient, specialist, primary, and private care, and $99 \%$ of all pharmacy dispatches in the region. In Sweden, a single prescription can be issued for up to 12 months and consists of up to four dispatches of medication, each of which lasts up to 3 months.
Using patient-specific identification codes, the data combine information from three sources: a regional health care database (VEGA) containing data on all health care utilization, including diagnostic codes (International Classification of Diseases 10th edition [ICD-10]), hospital costs (Diagnosis-Related Group [DRG] codes), and type of clinic (workplace codes); a drug register from the National Board of Health and Welfare (National Health Register), containing information on types, doses, and costs of all drugs dispensed from pharmacies (but not from hospitals); and a mortality register from the National Board of Health and Welfare listing dates and causes of all deaths. All data were anonymized and the data from all three registers were merged at the individual level using a unique personal identifier. The analysis period was July 1, 2005 to June 30, 2009, but historical data on comorbidities, which were available from 2000, were also used. Linking of the different data sources for the research performed was approved by the regional ethical committee in Gothenburg, Sweden.

All care costs available for the analysis, with the exception of primary care costs, were calculated from a third party payer perspective and were based on the NordDRG system, which iteratively updates DRG weights and costs every year, based on actual costs of care taken from the previous year. DRG codes specify the cost reimbursed for a care contact per individual. ${ }^{11}$ The costs for primary care were collected as the net cost of primary care for the region. Drug costs represent total prescription costs, including copay, and were taken from the Swedish drug registry, which covers all dispatches from pharmacies.

\section{Study population characteristics} Inclusion criteria

There is no specific ICD-10 code for chronic constipation; therefore, an algorithm was developed, based on discussions with clinical experts in chronic constipation, to identify cases in the data set. Patients were defined as having chronic constipation if they had at least two health care visits with recorded ICD-10 codes for constipation (ICD-10 code K59.0) within a 12-month period, or at least one primary constipation (K59.0) diagnosis and two dispatches of laxatives (Anatomical Therapeutic Chemical [ATC] code A06A*) during an 18-month period starting 6 months before the index date (the date of the first health care contact with constipation as a primary diagnosis). "Two dispatches" corresponds to 6 months of constipation medication, which is sufficient to satisfy the chronicity condition of the Rome III criteria. 


\section{Exclusion criteria}

Patients were excluded from the analysis if they were younger than 18 years at the index date, had ever received a diagnosis of irritable bowel syndrome (IBS; ICD-10 code K58*) or had received at least two dispatches of opioids (ATC code N02A) during the 6 months before or 12 months after the index date. Patients with a diagnosis of IBS were excluded because IBS with constipation can have a similar pathology to chronic constipation, but have a different symptom pattern and treatment pathway. ${ }^{1}$ Patients with a record of opioid use were excluded because they have a different recommended treatment pathway than other patients with chronic constipation and are likely to have different health care utilization patterns. ${ }^{1,12}$ To enable a 12-month follow-up period for all patients, individuals were also excluded if their first constipation diagnosis was after July 1, 2008.

\section{Data analysis}

Data on diagnoses, health care utilization, laxative use, and mortality were analyzed for the 12-month period following the index date. Calcium antagonist use (ATC code C $80^{*}$ ) has previously been linked to constipation and was investigated during the follow-up period. Five diagnosis-related comorbidities were explored on the a priori expectation that they could have an impact on chronic constipation based on medical opinion and population prevalence: ${ }^{13,14}$ Parkinson's disease (ICD-10 code G20*), type 2 diabetes mellitus (ICD-10 codes E11*-E14*), multiple sclerosis (ICD-10 code G35*), cardiac arrhythmia (ICD-10 codes I47*-I49*), and spinal cord injury (S14.0, S24.0, S34.0, T09.3, or T91.3). The occurrence of any of these comorbidities between the year 2000 and the end of the analysis period was recorded. The prevalence of these and other comorbidities was also assessed for the 12-month period following the index date. Comorbidities were stratified by sex and age group (18-49, 50-64, 65-74, and $\geq 75$ years). A statistical comparison between comorbidities in men and women was carried out using Pearson's chi-squared test with Yates' continuity correction.

To give a full overview of the resource utilization of patients with chronic constipation, health care contacts and drug use were separated into "constipation-related care" and "all other care", and were further stratified by sex and age group. Annual constipation-related care and all other care resource utilization were also estimated for comparison. Health care contacts were defined as being constipation-related based on the following diagnostic (ICD-10) codes: constipation (K59.0), anal fistula (K60.0, K60.1, K60.2, and K60.3), hemorrhoids (I84*), fecal impaction (K56.4), rectal prolapse (K62.3), and intestinal obstruction (K56.6); and procedure codes, ie, colectomy (JFB30, JFB31, JFB43, JFB44, JFH00, JFH01, JFH10, JFH11, JFH20, JFH30, JFH33, JFH40, and JFH96), rectoscopy (UJG02), colonoscopy (UJF32), hemorrhoid treatment (JHB00, JHB10, JHB20, JHB30, JHB40, and JHB96) and anal fistula treatment (JHD20, JHD30, and JHD33). Health care consultations with codes not included in the above list were classified as all other care. The length of stay was assessed and analyzed statistically using a Wilcoxon rank-sum test with continuity correction. All resource utilization and care contacts were normalized to an annual rate. The most recent year for which costs were available was 2009; costs for other years were inflated to equivalent 2009 values using the consumer price index for health care, provided by Statistics Sweden. ${ }^{15}$ Costs were in Swedish krona and were converted to costs in euros $(€)$ using the average exchange rate for 2009 ( $€ 1=10.74$ Swedish krona).

The use of laxatives (ATC code A06A*) and other drugs was assessed by the length of treatment, medication possession ratio, and treatment overlap; corresponding costs were also calculated. Only groups of ATC codes that appeared in more than ten treatment periods were recorded. Given that laxative pack sizes vary and range from one-day to 30-day treatment regimens, a standardized system developed by the World Health Organization (defined daily dose) ${ }^{16}$ which was fixed and applicable to all dispatches, was used. The length of treatment during the 12-month follow-up period was measured in time in days from the first to the last dispatch, plus a $20 \%$ grace period (defined daily dose multiplied by 1.2 ) to allow for inconsistencies in patient adherence to therapy. The medication possession ratio was the sum of defined daily doses dispatched during treatment divided by the length of treatment. In a separate analysis, patients who switched treatments (ie, for whom the first dispatch of one laxative occurred after the last dispatch of the previous one) and those who were treated with two or more laxatives at the same time were also identified (overlap, ie, two consecutive treatment periods in which the start of one period preceded the end of the previous period; add-on, ie, in which the first dispatch of one treatment period preceded the last dispatch of the previous period). Data on over-the-counter medications were not collected and therefore were not available for analysis.

Regression analysis of costs was performed to adjust for comorbidities and baseline demographics, and to determine which of these were associated with changes in the costs related to constipation. Covariates in this analysis included the following: sex; age group; mortality during follow-up; history of Parkinson's disease, multiple sclerosis, type 2 diabetes mellitus, spinal injury, or arrhythmia; and use of 
calcium antagonists. A generalized linear model was used, assuming a gamma distribution for costs on a log scale. All regressions were performed using $\mathrm{R}$ statistical software (R Foundation for Statistical Computing, Vienna, Austria). ${ }^{17}$ The Lsmeans package ${ }^{18}$ in $\mathrm{R}$ was used to estimate the adjusted annual mean cost for each stratum of sex and age group, followed by back-transformation through exponentiation.

\section{Results}

\section{Population demographics}

In total, 6,597 patients met the care contact and/or laxative inclusion criteria; after exclusion of the IBS population and patients who concomitantly used opioids, 4,043 unique patients were identified for further analysis (Figure 1). The mean (SD) age of this patient cohort at the index date was $67 \pm 18$ years and $60 \%$ were women (Table 1 ). Close to half of this population was 75 years of age or older (Table 1). The average follow-up time was 350 days.

\section{Morbidity and mortality}

Mortality was 7\% $(n=282)$ during the 12-month follow-up, and men had a higher mortality than women (Table 1). This was consistent across all age groups. Information on cause of death was not collected.
Care contact inclusion

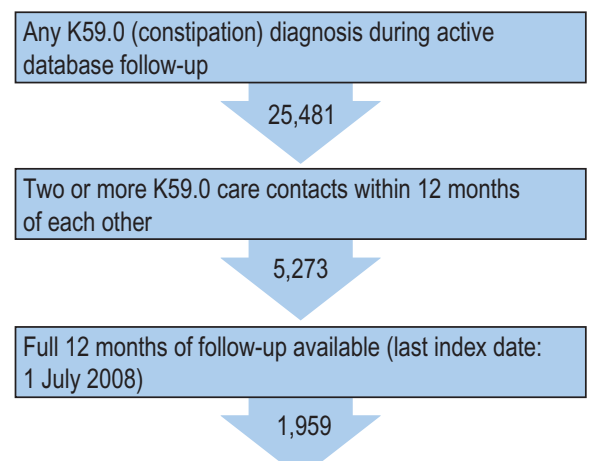

Laxative inclusion

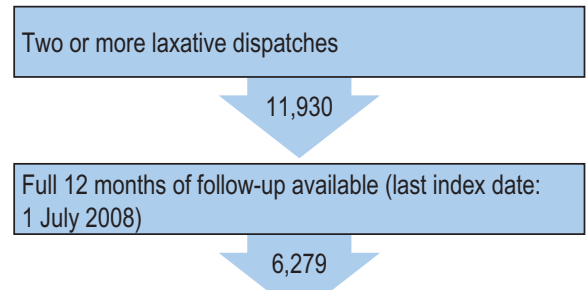

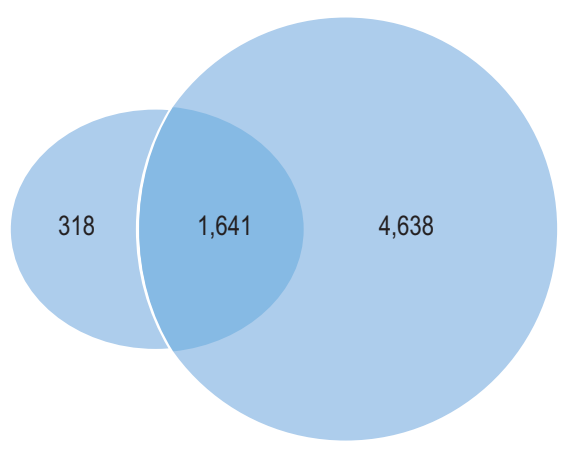

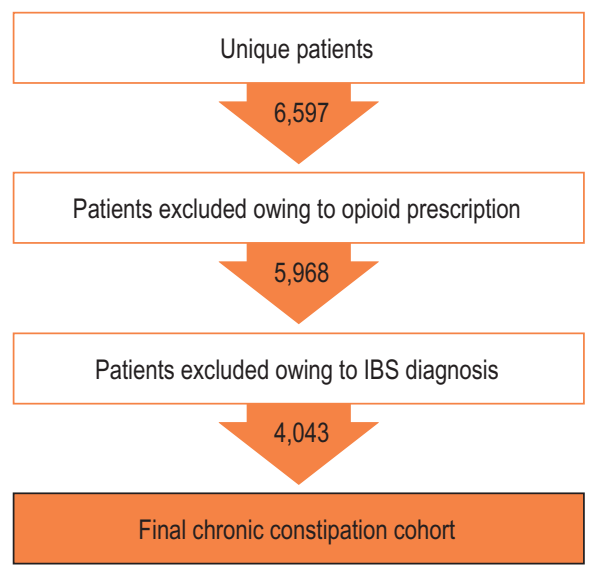

Figure I Application of inclusion and exclusion criteria for patient selection for chronic constipation identified by type of care contact or laxative use. Abbreviation: IBS, irritable bowel syndrome. 
Table I Baseline characteristics, prevalence of comorbidities from 2000 to the end of the analysis period, and mortality in the 12 months after the index date in patients with chronic constipation

\begin{tabular}{|c|c|c|c|c|c|c|c|c|}
\hline $\begin{array}{l}\text { Sex and } \\
\text { age }\end{array}$ & $\begin{array}{l}\text { Patients } \\
\text { n (\%) }\end{array}$ & $\begin{array}{l}\text { Parkinson's } \\
\text { disease }\end{array}$ & $\begin{array}{l}\text { Type } 2 \text { diabetes } \\
\text { mellitus }\end{array}$ & $\begin{array}{l}\text { Multiple } \\
\text { sclerosis }\end{array}$ & Arrhythmia & $\begin{array}{l}\text { Spinal } \\
\text { injury }\end{array}$ & $\begin{array}{l}\text { Calcium } \\
\text { antagonist use }\end{array}$ & $\begin{array}{l}\text { I2-month } \\
\text { mortality }\end{array}$ \\
\hline All patients & $4,043(-)$ & $2.5 \%$ & $11.4 \%$ & $1.0 \%$ & $15.4 \%$ & $0.3 \%$ & $14.6 \%$ & $7.0 \%$ \\
\hline \multicolumn{9}{|l|}{ Men } \\
\hline All ages & I,627 (-) & $3.1 \%$ & $15.4 \%$ & $1.0 \%$ & $19.1 \%$ & $0.6 \%$ & $15.8 \%$ & $9.2 \%$ \\
\hline $18-49$ years & $216(13)$ & $0.5 \%$ & $2.3 \%$ & $0.9 \%$ & $1.4 \%$ & $1.9 \%$ & $3.7 \%$ & $1.4 \%$ \\
\hline 50-64 years & $222(14)$ & $1.4 \%$ & $16.2 \%$ & $5.0 \%$ & $5.9 \%$ & $1.8 \%$ & $11.3 \%$ & $4.1 \%$ \\
\hline $65-74$ years & $319(20)$ & $4.1 \%$ & $19.4 \%$ & $0.9 \%$ & $14.1 \%$ & $0.6 \%$ & $17.6 \%$ & $4.1 \%$ \\
\hline$\geq 75$ years & $870(53)$ & $3.9 \%$ & $16.9 \%$ & $0.1 \%$ & $28.7 \%$ & $0.0 \%$ & $19.3 \%$ & $14.3 \%$ \\
\hline \multicolumn{9}{|l|}{ Women } \\
\hline All ages & $2,416(-)$ & $2.1 \%$ & $8.7 \%$ & $1.0 \%$ & $12.9 \%$ & $0.1 \%$ & $13.7 \%$ & $5.5 \%$ \\
\hline $18-49$ years & $565(23)$ & $0.2 \%$ & $2.3 \%$ & $0.9 \%$ & $1.6 \%$ & $0.2 \%$ & $0.7 \%$ & $0.0 \%$ \\
\hline 50-64 years & $388(16)$ & $1.0 \%$ & $5.2 \%$ & $2.3 \%$ & $4.9 \%$ & $0.3 \%$ & $7.0 \%$ & $1.8 \%$ \\
\hline $65-74$ years & $430(18)$ & $3.3 \%$ & $10.9 \%$ & $0.9 \%$ & $9.8 \%$ & $0.0 \%$ & $15.8 \%$ & $3.5 \%$ \\
\hline$\geq 75$ years & $\mathrm{I}, 033(43)$ & $3.0 \%$ & $12.6 \%$ & $0.7 \%$ & $23.4 \%$ & $0.0 \%$ & $22.6 \%$ & $10.7 \%$ \\
\hline
\end{tabular}

Cardiac arrhythmia ( $\mathrm{n}=623 ; 15 \%$ of patients) was the most common of the five diagnosis-related comorbidities that were specifically assessed, followed by type 2 diabetes mellitus $(n=460 ; 11 \%)$, as taken from historical records (available from 2000) to the end of the follow-up period. Men had a significantly $(P<0.05)$ higher rate than women of each of the diagnosis-related comorbidities studied except for multiple sclerosis $(P=0.899$; Table 1). Fifteen per cent of patients $(\mathrm{n}=589)$ were prescribed calcium antagonists during the follow-up period. Of these, the majority $(n=401 ; 68 \%)$ were aged $\geq 75$ years and only $2 \%(n=12)$ were aged $18-49$ years. Calcium antagonist use did not differ significantly between men and women $(P=0.077)$.

When data for other comorbidities during the follow-up period were examined based on ICD-10 codes, hypertension $(\mathrm{n}=901 ; 22 \%)$ and abdominal/pelvic pain $(\mathrm{n}=777 ; 19 \%)$ were found to be the most commonly diagnosed conditions. Looking specifically at inpatient health care contacts using DRG codes, the most common were for uncomplicated abdominal pain/gastroenteritis $(n=521 ; 49 \%)$ and complicated abdominal pain/gastroenteritis $(\mathrm{n}=361 ; 34 \%)$. Diagnoses of other chronic bowel diseases were identified in a small proportion of patients, ie, 15 patients $(0.3 \%)$ had a diagnosis of Crohn's disease (ICD-10 code K50), 29 (0.7\%) had a diagnosis of ulcerative colitis (ICD-10 code K51), and $67(1.7 \%)$ had a diagnosis of colon cancer (ICD-10 code $\mathrm{C} 18)$.

\section{Resource utilization}

Unadjusted resource utilization data were calculated. Patients with chronic constipation had a mean (SD) of $2.3 \pm 7.5$ constipation-related health care contacts as well as a mean (SD) of $15.2 \pm 19.5$ all other health care contacts during the 12-month follow-up period (Table 2). The mean number of both constipation-related health care contacts and all other health care contacts increased with age and was similar for men and women (Table 2).

Constipation-related complications and procedures were relatively infrequent. Hemorrhoids were the most common constipation-related complication, affecting about $6 \%$ of patients per year. Rectoscopy (10\% of patients per year) and colonoscopy ( $9 \%$ of patients per year) were the most common constipation-related procedures. Anal fistula, intestinal obstruction, and colectomy accounted for $1.2 \%$ of complications.

Table 2 Mean annual number of constipation-related health care and other health care contacts in patients with chronic constipation

\begin{tabular}{llll}
\hline $\begin{array}{l}\text { Sex and } \\
\text { age }\end{array}$ & $\begin{array}{l}\text { Constipation- } \\
\text { related health } \\
\text { care contacts }\end{array}$ & $\begin{array}{l}\text { All other } \\
\text { health care } \\
\text { contacts }\end{array}$ & $\begin{array}{l}\text { All health } \\
\text { care } \\
\text { contacts }\end{array}$ \\
\hline Men & & & \\
All ages & $2.5(5.8)$ & $16.8(21.5)$ & $19.2(24.6)$ \\
18-49 years & $1.9(2.2)$ & $10.7(14.4)$ & $12.6(14.9)$ \\
$50-64$ years & $1.9(1.8)$ & $16.2(21.8)$ & $18.1(22.2)$ \\
$65-74$ years & $2.4(5.5)$ & $18.7(25.7)$ & $21.1(27.6)$ \\
$\geq 75$ years & $2.8(7.0)$ & $17.7(21.0)$ & $20.5(25.8)$ \\
Women & & & $16.3(23.1)$ \\
All ages & $2.2(8.5)$ & $14.1(18.0)$ & $14.0(17.8)$ \\
I8-49 years & $1.8(1.1)$ & $12.3(17.7)$ & $15.8(16.8)$ \\
$50-64$ years & $1.9(1.6)$ & $13.9(16.4)$ & $18.0(26.4)$ \\
$65-74$ years & $2.0(4.5)$ & $16.0(22.9)$ & $17.0(25.9)$ \\
$\geq 75$ years & $2.7(12.5)$ & $14.3(16.3)$ & $17.5(23.7)$ \\
Overall & $2.3(7.5)$ & $15.2(19.5)$ &
\end{tabular}

Note: Data are expressed as the mean (standard deviation). 
In total, $95 \%$ of constipation-related hospital outpatient health care contacts were with a physician, 4\% were with a nurse, and the remaining contacts were with another health care professional, such as a therapist, counselor, or technician. By comparison, only $55 \%$ of all other outpatient health care contacts were with a physician, $28 \%$ were with a nurse, and $18 \%$ were with another health care professional. In primary health care, $99 \%$ and $1 \%$ of contacts were with physicians and nurses, respectively, for constipation-related contacts and 39\%, 41\%, and 19\% with physicians, nurses, and other health care professionals, respectively, for all other health care contacts. Further exploration of the treatment patterns and type of care provided showed that the highest proportions of health care contacts for inpatients (patients who were hospitalized) and outpatients (those visiting a clinic for less than one day) were in surgical clinics (65\% of inpatients and $43 \%$ of outpatients). The next most common workplace codes for inpatients were internal medicine clinics $(16 \%)$ and gastrointestinal clinics (6\%). By comparison, $17 \%$ of outpatient visits were to a gastrointestinal clinic, $10 \%$ to a gastroenterology clinic, and $19 \%$ to emergency care. The mean (SD) inpatient stay was $2.4 \pm 15.6$ days per year for constipation-related care and $7.5 \pm 25.8$ days per year for all other care. Interestingly, while the mean (SD) duration of hospital stay was very similar for men and women for constipation-related care, it was significantly higher for men (10.2 \pm 31.2 days) than for women for all other care $(5.7 \pm 21.2$ years; $P<0.001)$.

The annual mean (SD) number of health care contacts increased with age, from $12.6 \pm 24.6$ in men aged $18-49$ years
(14.0 \pm 17.8 in women) to $20.5 \pm 25.8$ in men over the age of 75 years (17.0 \pm 23.7 in women). The annual frequency of constipation-related procedures also increased with age, with rectoscopy and colonoscopy being most frequent in patients aged 65-74 years (rectoscopy, 0.11 per year in men and 0.14 in women; colonoscopy, 0.29 in men and 0.10 in women), and least frequent in patients aged 18-49 years (rectoscopy, 0.07 per year in men and 0.08 in women; colonoscopy, 0.04 in men and 0.05 in women).

\section{Health care costs}

The unadjusted mean (SD) annual cost of constipationrelated care was $€ 1,642 \pm € 14,618$, in addition to the cost of all other care, which was $€ 5,944 \pm € 18,209$ (Table 3). Men incurred higher costs than women, both for chronic constipation-related care (mean [SD], men $€ 2,188 \pm € 20,644$ versus women $€ 1,274 \pm € 8,286)$ and for all other care (mean [SD], men $€ 7,647 \pm € 19,756$ versus women $€ 4,797 \pm € 16,997)$. In general, costs increased with age (Table 3 ).

Regression analysis indicated that age, sex, mortality during follow-up, and all comorbidities of interest were significant predictors of chronic constipation costs; for all other care, only age, sex, mortality during follow-up, type 2 diabetes mellitus, and arrhythmia were significantly associated with costs (Table 4). Taking this into account, costs were adjusted for sex, age group, mortality during follow-up, and comorbidities. The adjusted annual mean cost of constipation-related care was $€ 1,067$ (95\% CI $€ 951-€ 1,199)$ for men and $€ 839$ (95\% CI €764-922) for women; the corresponding numbers for all other care were

Table 3 Annual mean costs in patients with chronic constipation

\begin{tabular}{|c|c|c|c|c|c|c|}
\hline & \multicolumn{3}{|l|}{ Unadjusted } & \multicolumn{3}{|c|}{ Adjusted for covariates } \\
\hline & $\begin{array}{l}\text { Constipation- } \\
\text { related costs ( } €)\end{array}$ & $\begin{array}{l}\text { Other } \\
\text { costs }(€)\end{array}$ & $\begin{array}{l}\text { Total } \\
\text { costs }(€)\end{array}$ & $\begin{array}{l}\text { Constipation- } \\
\text { related costs ( } € \text { ) }\end{array}$ & Other costs $(€)$ & Total costs $(€)$ \\
\hline \multicolumn{7}{|l|}{ Men } \\
\hline All ages & $2,188(20,644)$ & $7,647(19,756)$ & $9,835(30,379)$ & I,067 (95I-I,I99) & $5,260(4,8 \mid 5-5,747)$ & $6,328(5,850-6,845)$ \\
\hline $18-49$ years & $860(2,589)$ & $4,378(10,118)$ & $5,238(10,955)$ & $838(693-1,014)$ & $5,040(4,357-5,830)$ & $5,867(5,157-6,676)$ \\
\hline 50-64 years & $\mathrm{I}, 488(5,705)$ & $5,153(9,237)$ & $6,641(11,978)$ & I,I 72 (960-I,43I) & $5,165(4,433-6,017)$ & $6,334(5,53 \mid-7,252)$ \\
\hline 65-74 years & $3,976(44,527)$ & $7,922(18,386)$ & I I,898 (49,298) & I,I03 (922-I,320) & $5,777(5,037-6,626)$ & $6,874(6,087-7,763)$ \\
\hline$\geq 75$ years & $2,04 \mid(8,139)$ & $8,992(23,518)$ & II,033 (29,59I) & I, $199(1,052-1,365)$ & $5,091(4,608-5,624)$ & $6,278(5,747-6,858)$ \\
\hline \multicolumn{7}{|l|}{ Women } \\
\hline All ages & I,274 $(8,286)$ & $4,797(16,997)$ & $6,071(19,975)$ & 839 (764-922) & $3,992(3,716-4,289)$ & $4,859(4,559-5,178)$ \\
\hline $18-49$ years & $474(635)$ & $3,027(6,093)$ & $3,501(6,235)$ & 659 (557-779) & $3,825(3,365-4,349)$ & $4,505(4,020-5,048)$ \\
\hline $50-64$ years & $974(3,28 I)$ & $4,207(9,992)$ & $5,|8|(\mid I, 84 I)$ & $922(765-1, I 10)$ & $3,920(3,399-4,521)$ & $4,863(4,285-5,518)$ \\
\hline $65-74$ years & $789(2,543)$ & $4,844(16,5 \mid 3)$ & $5,633(17,934)$ & $868(731-1,029)$ & $4,385(3,848-4,996)$ & $5,278(4,70 \mathrm{I}-5,925)$ \\
\hline$\geq 75$ years & $2,029(12,366)$ & $5,970(22,4 \mid 4)$ & $7,999(26,822)$ & $942(835-1,064)$ & $3,864(3,520-4,240)$ & $4,820(4,438-5,234)$ \\
\hline Overall & $1,642(14,618)$ & $5,944(18,209)$ & $7,586(24,760)$ & 951 (929-973) & $4,421(4,339-4,504)$ & $5,388(5,284-5,494)$ \\
\hline
\end{tabular}

Note: Values are per patient and expressed in euros $(€)$ as mean (standard deviation) for unadjusted results and mean (95\% confidence interval) for results adjusted for sex, age group, mortality during follow-up, and comorbidities. 
Table 4 Regression analysis carried out with constipation-related costs and other costs, using age group, sex, and comorbidities as covariates

\begin{tabular}{lll}
\hline Variable & $\begin{array}{l}\text { Other costs, } \\
\text { proportional } \\
\text { cost increase } \\
(\boldsymbol{P} \text {-value) }\end{array}$ & $\begin{array}{l}\text { Constipation- } \\
\text { related costs, } \\
\text { proportional cost } \\
\text { increase }(\boldsymbol{P} \text {-value) }\end{array}$ \\
\hline Men & $\mathrm{I} .32(<0.0005)$ & $\mathrm{I} .27(0.00 \mathrm{I})$ \\
Age 50-64 years & $\mathrm{I} .02(0.79 \mathrm{I})$ & $\mathrm{I} .40(0.006)$ \\
Age 65-74 years & $\mathrm{I} .15(0.125)$ & $\mathrm{I} .32(0.0 \mathrm{I} 8)$ \\
Age $\geq 75$ years & $\mathrm{I} .0 \mathrm{I}(0.899)$ & $\mathrm{I} .43(0.0005)$ \\
Died during follow-up & $7.76(<0.0005)$ & $\mathrm{I} 2.67(<0.0005)$ \\
Parkinson's disease & $\mathrm{I} .34(0.085)$ & $\mathrm{I} .26(0.297)$ \\
Type 2 diabetes mellitus & $\mathrm{I} .26(0.007)$ & $\mathrm{I} .27(0.033)$ \\
Multiple sclerosis & $\mathrm{I} .48(0.138)$ & $2.2 \mathrm{I}(0.022)$ \\
Arrhythmia & $\mathrm{I} .50(<0.0005)$ & $\mathrm{I} .3 \mathrm{I}(0.008)$ \\
Spinal injury & $0.83(0.705)$ & $\mathrm{I} . \mathrm{II}(0.867)$ \\
Calcium antagonist use & $\mathrm{I} .04(0.594)$ & $\mathrm{I} .15(0.168)$ \\
\hline
\end{tabular}

Notes: In order to estimate costs, coefficients were back-transformed through exponentiation. The exp (intercept) corresponds to the average annual cost of chronic constipation for a baseline individual, in this case a female aged between 18 and 49 years who was alive at end of follow-up and did not have any of the comorbidities.

$€ 5,260$ (95\% CI €4,815-5,747) for men and €3,992 (95\% CI $€ 3,716-4,289$ ) for women (Table 3). These adjustments also indicated that men had, on average, 30\% higher total costs than women, even after controlling for differences in age and comorbidities. The overall adjusted annual costs were estimated to be $€ 951$ (95\% CI €929-973) for chronic constipation-related care and $€ 4,421(95 \% \mathrm{CI} € 4,339-4,505)$ for all other care (Table 3).

\section{Use of medication}

During the 12-month follow-up period, patients with chronic constipation received a mean (SD) of $4 \pm 3.7$ laxative dispatches; in comparison, there were 43 dispatches of other drugs per patient. Approximately $89 \%(n=3,594)$ of patients received one or more different laxatives, while $17 \%(n=686)$ received more than three different laxatives. The most commonly prescribed laxative was polyethylene glycol (ATC code A06AD65), which was prescribed for a mean (SD) of $46 \pm 44$ days. Only $11 \%$ of patients had no dispatches of laxatives. There was no obvious variation between the sexes in the pattern of laxative treatment (data not shown). The only clear difference between age groups was in the proportion of patients who received no laxative dispatches, which was $7 \%-9 \%$ in patients aged $18-74$ years but $13 \%-16 \%$ in those aged $\geq 75$ years.

The mean duration of laxative treatment ranged from 2 days for one type of laxative (ATC code A06AD10; mineral salts in combination) to over 100 days for other laxatives
(ATC codes A06AD11 [lactulose], A06AD12 [lactitol], and A06AD15 [polyethylene glycol]). The mean (SD) medication possession ratio during each dispatch tended to be about 1.00, but varied across laxative types, ranging from $0.84 \pm 0.01$ for A06AX02 (carbon dioxide-producing drugs) to $1.08 \pm 0.57$ for A06AD11 (lactulose).

In total, $48 \%(n=1,941)$ of patients had overlapping treatment periods that involved the use of one or more laxatives. Of these, $67 \%(\mathrm{n}=1,294)$ switched laxatives, $50 \%(\mathrm{n}=975)$ had add-on treatment, and a total of $17 \%(n=328)$ both switched laxatives and had add-on treatment.

Unadjusted laxative costs amounted to a mean (SD) annual cost of $€ 61 \pm € 74$ per patient (Table 5). No clear differences in mean (SD) costs were observed between men

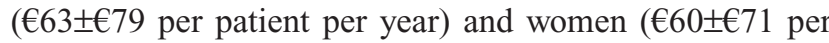
patient per year). Laxative costs constituted about $10 \%$ of total drug spending, and the costs of other drugs for these individuals amounted to mean (SD) $€ 624 \pm € 1,138$ per patient per year (Table 5). Although laxative costs did not appear to vary with demographic strata, other drug costs were higher in men (mean $[\mathrm{SD}] € 713 \pm € 1,296)$ than in women (mean [SD] $€ 563 \pm € 1,013$ ), and peaked in men aged 65-74 years (mean

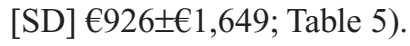

\section{Discussion}

This was a systematic retrospective cohort study of health care records in Sweden, the aim of which was to estimate the economic burden of chronic constipation in this health care setting. The data used for the study included patient data from the vast majority of the population of Västra Götaland. ${ }^{10}$ In total, approximately $2 \%$ of this population was identified as having a primary diagnosis code of constipation. After application of strict inclusion and

Table 5 Annual unadjusted laxative and nonlaxative costs

\begin{tabular}{lll}
\hline Sex and age & Laxative costs $(\boldsymbol{\epsilon})$ & Other drug costs $(\boldsymbol{\epsilon})$ \\
\hline Men & & \\
All ages & $63(79)$ & $713(1,296)$ \\
I8-49 years & $56(80)$ & $531(1,247)$ \\
$50-64$ years & $60(98)$ & $819(2,264)$ \\
$65-74$ years & $65(76)$ & $926(1,491)$ \\
$\geq 75$ years & $64(73)$ & $653(782)$ \\
Women & & \\
All ages & $60(71)$ & $563(1,013)$ \\
I8-49 years & $54(90)$ & $443(1,237)$ \\
$50-64$ years & $58(66)$ & $696(1,598)$ \\
$65-74$ years & $61(60)$ & $619(658)$ \\
$\geq 75$ years & $63(63)$ & $556(64 I)$ \\
Total & $61(74)$ & $624(1,138)$ \\
\hline
\end{tabular}

Note: All values are expressed as annual mean (standard deviation) costs per patient. 
exclusion criteria, $16 \%$ of these were defined as having chronic constipation. Previous estimates of the prevalence of constipation vary depending on the method used to identify patients with the condition, but range from $1.7 \%$ to $20 \%$ in Sweden ${ }^{6}$ and from $2.5 \%$ to $79 \%$ in other developed countries. ${ }^{2}$ Approximately two thirds of patients in this study were women, consistent with the results of other studies performed in Europe, as well as in North America and Oceania. ${ }^{2,419}$ This may also be a reflection of the fact that women are more likely than men to seek health care advice for constipation. ${ }^{20}$ However, it should be noted that men had a similar consultation rate to women in the present study. Mortality was 7\% during the 12-month follow-up period; men had a higher mortality than women, in line with findings in the general population. ${ }^{21}$

A high proportion of the patients identified in this study were elderly; about half were aged 75 years or older. Consistent with this, most of the resource utilization and costs associated with the patients in this study were not constipation-related, although costs and resource use related to constipation also increased with age. Two recent cohort studies have assessed the economic burden of chronic constipation in Belgium and the Netherlands. ${ }^{22,23}$ These used similar inclusion criteria to the present study to identify patient records from a Belgian hospital database ${ }^{22}$ and a Dutch health insurance claims database. ${ }^{23}$ In the former, $38.8 \%$ of the population identified were aged 65 years or over, and mean annual chronic constipation-related hospital costs were $€ 441$ per patient; in the latter, the mean age of the population with chronic constipation was 64 years and the mean annual cost of constipation was $€ 367$ per patient. The younger age of the populations identified in these studies compared with the present analysis (47\% aged at least 75 years, mean age 67 years) may highlight differences in data inputting or in the practice patterns of each country. One possible explanation for the higher prevalence of older patients in this study is that elderly patients are more likely to consult a physician for their illness. ${ }^{5}$ Examining an age-matched control population would help to address this possibility, but was not within the scope of the current analysis.

This study shows that a large proportion of patients with chronic constipation have at least one comorbidity. Hypertension was the most commonly reported comorbidity, recorded for $22 \%$ of patients, which is consistent with its global prevalence. ${ }^{24}$ In addition, $11 \%$ of patients had type 2 diabetes mellitus and 2\% had Parkinson's disease. The prevalence of type 2 diabetes mellitus is higher than that in the general Swedish population, estimates of which are similar to European and global prevalence estimates, at approximately $4 \%$ of the population. ${ }^{25,26}$ Similarly, the prevalence of Parkinson's disease in industrialized countries has been calculated to be $0.6 \%$, rising to $1 \%$ in individuals aged over 60 years. ${ }^{27}$ These results are consistent with the evidence that chronic constipation is more common in patients with type 2 diabetes or Parkinson's disease than in the general population. Indeed, it has previously been shown that $20 \%-44 \%$ of patients with diabetes mellitus in a US community reported constipation or the use of laxatives. ${ }^{28}$ In addition, certain anti-Parkinsonian drugs have been linked to constipation. ${ }^{29}$ It should also be noted that the prevalence of these diseases increases with age, so the high levels seen in the present study may reflect the high mean age of the population investigated.

Patients with a diagnosis of chronic constipation had unadjusted annual costs of $€ 7,586$, made up of $€ 1,642$ for patient visits directly related to constipation and $€ 5,944$ for visits due to other comorbid conditions. When these costs were adjusted for underlying patient characteristics (age, sex, and comorbidities), they were found to total $€ 5,388$, including $€ 951$ for chronic constipation-related health care and $€ 4,421$ for comorbidity-related health care. These figures, along with the high rate of comorbidities in these patients, indicate that chronic constipation is frequently accompanied by other health conditions, which have a substantial impact on use of resources. As discussed above, this high rate of comorbidities may be related to the high age of the population being studied. Nevertheless, costs directly related to constipation make up over $20 \%$ of the total cost of care in these patients. By comparison, estimates of annual direct health care costs related to chronic obstructive pulmonary disease range from $€ 1,500$ to $€ 2,000$ (1999 costs) per patient per year in Sweden based on patient surveys. ${ }^{30,31}$

The mean annual cost of constipation-related medication per patient was approximately $€ 60$; however, this is likely to be an underestimate of the total drug costs. One reason for this is that over-the-counter medications and hospital drugs are not captured in the national drug register, so could not be accounted for in the current analyses. Secondly, new promotility drugs for the treatment of chronic constipation, such as prucalopride and linaclotide, were not available, and lubiprostone had been available for less than 1 year on the Swedish market at the time of the study. The use of these drugs will therefore not have been captured in the present study. They differ in price and efficacy compared with laxative treatments, and it would be interesting to investigate 
how introduction of these drugs has impacted on resource use and costs.

A large proportion of individuals were prescribed at least two types of laxatives during the study period (requiring additional prescriptions and health care visits). In addition, the medication possession ratio was greater than one for some laxatives, suggesting that these were being prescribed at doses higher than the defined daily dose. Nearly one half of patients switched laxatives during the year, and firstline therapy was frequently supplemented with additional medication. This is consistent with the results of a recent patient survey carried out in ten European countries, which showed that $28 \%$ of respondents were dissatisfied with their current laxative treatment and that the majority were interested in other treatments. ${ }^{32}$

This is the first study to examine systematically the health care burden and costs associated with chronic constipation in Sweden. However, several limitations to the study should be noted. One limitation is that the study lacks a control group against which to compare health care costs and resource utilization. Secondly, although patients taking opioids were excluded from the study, patients taking antipsychotics, calcium channel blockers, and anticholinergic agents, who may have visited their physician with a primary complaint of constipation, were not excluded. In addition, because nonprescription drugs were not captured in the database, the use and cost of over-the-counter laxatives were not captured.

Because there is no single ICD-10 code for chronic constipation, patients with the condition had to be identified using a predefined combination of diagnostic codes. Each code represents a diagnosis of constipation, but patients do not necessarily have to meet the Rome III criteria to receive a constipation-related diagnostic code. To allow for the lack of a code that represents the chronicity of constipation, a repeated patient diagnosis of constipation was required. In addition, for patients to be classified as having functional chronic constipation, only data for individuals with a primary diagnosis of constipation were analyzed, limiting the inclusion of those with constipation secondary to other factors, such as medications or underlying diseases. In light of the overlap in the symptoms of chronic constipation and IBS, patients who had ever received an IBS diagnosis were also excluded from the study; however, patients with IBS but without a diagnosis code recorded during the study period may still have been included in the study population. The high rate of abdominal pain, a predominant symptom of constipation-predominant IBS, in the patients identified in this study might support this idea; however, if constipation rather than pain was considered by the patient to be their predominant symptom, their condition should have been classified as chronic constipation rather than IBS. ${ }^{1}$ It should also be noted that patients with diagnoses of other chronic conditions associated with symptoms of constipation that could affect the interpretation of the results, such as colon cancer or other bowel disorders, ${ }^{29}$ were not excluded from the analysis. However, diagnoses of these conditions were only found in a small proportion of patients and were not expected to substantially affect the study conclusions. Similarly, some of the procedures and complications that were defined in this study as constipation-related (eg, colectomy) may also have been used to treat other conditions not directly related to constipation in these patients. These procedures made up only a small proportion of overall complications (1.2\%) but are high in cost and may overestimate the total resource use burden.

Diagnoses of constipation before the start of data collection (in 2005) were not identified, and therefore it was not possible to tell whether an initial diagnosis of constipation within the analysis corresponded to an incident case. On the other hand, given the chronic nature of the disease, which affects many people for over a decade, ${ }^{3}$ this study will have picked up a cross-section of the population with chronic constipation during the analysis period.

In conclusion, the adjusted mean annual health care costs for patients with chronic constipation were $€ 5,388$ per patient, including $€ 951$ for constipation-related health care. The patients also incurred annual prescription drug costs of $€ 685$, about $10 \%$ of which was attributable to laxatives. Future analyses with an age-matched comparator group would help to further distinguish the costs directly related to constipation from those due to other age-related complaints. It will be interesting to investigate how the recent introduction of new nonlaxative constipation treatments will impact on health care resource use and costs in these patients.

\section{Acknowledgments}

We thank Emil Löfroth for his involvement in the design and planning of the study, and Dr A Emmanuel and Dr Patricia Robinson for their discussions in developing an algorithm to identify patients with chronic constipation.

\section{Author contributions}

SBW was involved in the study design as well as analysis and presentation of the data. AJ proposed the study design and was involved in interpretation and analysis of the data. $\mathrm{PH}$ was also involved in analysis and interpretation of the data. All authors were involved in the preparation and critical 
revision of the manuscript and approved the final version of this paper, including the authorship list.

\section{Disclosure}

$\mathrm{PH}$ is an employee of Shire, Wayne, PA, USA. AJ is an employee of Shire, Eysins, Switzerland. Shire develops and manufactures drugs to treat gastrointestinal disorders, including chronic constipation. SBW is an employee of IMS Health, which received consultancy fees from Shire Movetis NV, Turnhout, Belgium, to conduct this study. This research was funded by Shire Movetis NV, Turnhout, Belgium. Under the direction of the authors, Rosalind Morley, an employee of PharmaGenesis ${ }^{\mathrm{TM}}$, London, UK, provided writing assistance for this publication, funded by Shire Movetis NV, Turnhout, Belgium. Editorial assistance with fact-checking, copyediting, formatting, and proofreading was provided by Oxford PharmaGenesis ${ }^{\text {TM }}$ Ltd and funded by Shire Movetis NV, Turnhout, Belgium. Slavka Baronikova from Shire, Diegem, Belgium, also edited the manuscript and reviewed it for scientific accuracy. Although the sponsor was involved in the design, collection, analysis, interpretation, and fact-checking of information, the content of this manuscript, its ultimate interpretation, and the decision to submit it for publication was made independently by the authors. The authors report no other conflicts of interest in this work.

\section{References}

1. Rome III diagnostic criteria for functional gastrointestinal disorders. Available from: http://www.romecriteria.org/assets/pdf/19_RomeIII_ apA_885-898.pdf. Accessed October 3, 2013.

2. Mugie SM, Benninga MA, Di Lorenzo C. Epidemiology of constipation in children and adults: a systematic review. Best Pract Res Clin Gastroenterol. 2011;25(1):3-18.

3. Johanson JF, Kralstein J. Chronic constipation: a survey of the patient perspective. Aliment Pharmacol Ther. 2007;25(5): 599-608.

4. Suares NC, Ford AC. Prevalence of, and risk factors for, chronic idiopathic constipation in the community: systematic review and meta-analysis. Am J Gastroenterol. 2011;106(9):1582-1591.

5. Sandler RS, Jordan MC, Shelton BJ. Demographic and dietary determinants of constipation in the US population. Am J Public Health. 1990;80(2):185-189.

6. Walter S, Hallbook O, Gotthard R, Bergmark M, Sjodahl R. A populationbased study on bowel habits in a Swedish community: prevalence of faecal incontinence and constipation. Scand J Gastroenterol. 2002;37(8):911-916.

7. Nyrop KA, Palsson OS, Levy RL, et al. Costs of health care for irritable bowel syndrome, chronic constipation, functional diarrhoea and functional abdominal pain. Aliment Pharmacol Ther. 2007;26(2): 237-248.

8. Singh G, Lingala V, Wang $H$, et al. Use of health care resources and cost of care for adults with constipation. Clin Gastroenterol Hepatol. 2007;5(9):1053-1058.

9. Wilhelmsen L, Welin L, Oden A, Bjornberg A. Saving lives, money and resources: drug and $\mathrm{CABG} / \mathrm{PCI}$ use after myocardial infarction in a Swedish record-linkage study. Eur J Health Econ. 2010;11(2):177-184.
10. Statistics Sweden. Population in the country, counties and municipalities on 31/12/2011 and Population Change in 2011. Available from: http://www.scb.se/Pages/TableAndChart__25897.aspx. Accessed October 3, 2013.

11. Nordic DRG user's manual version 2012 NC PR1. Available from: http://www.norddrg.net/norddrgmanual/NordDRG_2012_NC/index. htm. Accessed October 3, 2013.

12. National Institute for Health and Care Excellence. Clinical knowledge summary. 2013. Available from: http://cks.nice.org.uk/constipation\#!s cenariorecommendation:1. Accessed October 3, 2013.

13. Choung RS, Branda ME, Chitkara D, et al. Longitudinal direct medical costs associated with constipation in women. Aliment Pharmacol Ther. 2011;33(2):251-260.

14. Leung L, Riutta T, Kotecha J, Rosser W. Chronic constipation: an evidence-based review. J Am Board Fam Med. 2011;24(4):436-451.

15. Statistics Sweden. Consumer price index. Available from: http://www. scb.se/Pages/TableAndChart__33907.aspx. Accessed October 3, 2013.

16. World Health Organisation Collaborating Centre for Drug Statistics Methodology. Definition and general considerations. Available from: http://www.whocc.no/ddd/definition_and_general_considera/. Accessed October 3, 2013.

17. R Development Core Team. 2011. R: a language and environment for statistical computing. R Foundation for Statistical Computing. Vienna, Austria. Available from: http://www.R-project.org. Accessed October 3, 2013.

18. Russell V Lenth. 2013. 1smeans: Least-squares means. R package version 1.06-06. Available from: http://CRAN.R-project.org/package=lsmeans. Accessed October 3, 2013.

19. Chang J, Locke GR, McNally M, et al. Impact of functional gastrointestinal disorders on survival in the community. Am J Gastroenterol. 2010;105(4):822-832.

20. Irvine EJ, Ferrazzi S, Pare P, Thompson WG, Rance L. Health-related quality of life in functional GI disorders: focus on constipation and resource utilization. Am J Gastroenterol. 2002;97(8):1986-1993.

21. Index Mundi. Sweden - mortality rate. Available from: http://www. indexmundi.com/facts/sweden/mortality-rate. Accessed October 3, 2013.

22. Chevalier P, Lamotte M, Joseph A, Dubois D, Boeckxstaens G. In-hospital costs associated with chronic constipation in Belgium: a retrospective database study. Neurogastroenterol Motil. 2014;26(3):368-376.

23. Dik VK, Siersema P, Smeets HM, Van Oijen MGH. Direct medical costs after new chronic constipation diagnosis depend on disease course. Abstract P0963 presented at the 20th United European Gastroenterology Week, Amsterdam, The Netherlands, October 20-24, 2012.

24. Hajjar I, Kotchen JM, Kotchen TA. Hypertension: trends in prevalence, incidence, and control. Annu Rev Public Health. 2006;27:465-490.

25. Jansson SP, Andersson DK, Svardsudd K. Prevalence and incidence rate of diabetes mellitus in a Swedish community during 30 years of follow-up. Diabetologia. 2007;50(4):703-710.

26. Masso-Gonzalez EL, Johansson S, Wallander MA, Rodriguez LA. Trends in the prevalence and incidence of diabetes in the UK: 1996-2005. J Epidemiol Community Health. 2009;63(4):332-336.

27. de Lau LM, Breteler MM. Epidemiology of Parkinson's disease. Lancet Neurol. 2006;5(6):525-535.

28. Shakil A, Church RJ, Rao SS. Gastrointestinal complications of diabetes. Am Fam Physician. 2008;77(12):1697-1702.

29. Bharucha AE, Pemberton JH, Locke GR 3rd. American Gastroenterological Association technical review on constipation. Gastroenterology. 2013;144(1):218-238.

30. Jansson SA, Andersson F, Borg S, Ericsson A, Jonsson E, Lundback B. Costs of COPD in Sweden according to disease severity. Chest. 2002;122(6):1994-2002.

31. Jansson SA, Lindberg A, Ericsson A, et al. Cost differences for COPD with and without physician-diagnosis. COPD. 2005;2(4):427-434.

32. Muller-Lissner S, Tack J, Feng Y, Schenck F, Specht Gryp R. Levels of satisfaction with current chronic constipation treatment options in European Internet survey. Aliment Pharmacol Ther. 2013;37(1): 137-145. 


\section{Publish your work in this journal}

ClinicoEconomics \& Outcomes Research is an international, peerreviewed open-access journal focusing on Health Technology Assessment, Pharmacoeconomics and Outcomes Research in the areas of diagnosis, medical devices, and clinical, surgical and pharmacological intervention. The economic impact of health policy and health systems organization also constitute important areas of coverage. The manuscript management system is completely online and includes a very quick and fair peer-review system, which is all easy to use. Visit http://www.dovepress.com/testimonials.php to read real quotes from published authors.

Submit your manuscript here: http://www.dovepress.com/clinicoeconomics-and-outcomes-research-journal 